\title{
Job matching, technological progress, and worker-provided on-the-job training
}

\author{
Mário Centeno ${ }^{\mathrm{a}, \mathrm{b}, \mathrm{c}}$, Márcio Corrêa ${ }^{\mathrm{d}, \mathrm{e}, *}$ \\ a Banco de Portugal, Economic Research Department, Lisboa, Portugal \\ b Instituto Superior de Economia e Gestão, ISEG/UTL, Lisboa, Portugal \\ c UECE (Research Unit on Complexity and Economics) Lisboa, Portugal \\ d Universidade Federal do Ceará, Campus de Sobral, Sobral, Brazil \\ e Centro de Pós-Graduação em Economia, CAEN/UFC, Fortaleza, Brazil
}

\section{A R T I C L E I N F O}

\section{Article history:}

Received 24 April 2007

Received in revised form 5 August 2010

Accepted 9 August 2010

Available online 27 August 2010

\section{JEL classification:}

$\mathrm{J} 24$

J63

J64

Keywords:

Job creation

Job destruction

Human capital

\section{A B S T R A C T}

We show that greater technological progress is associated with a lower (higher) probability of worker investment in firm-specific human capital if the technology is of creative destruction (renovation) type. The impact of human capital investments on labor market outcomes depends on the type of investment.

(C) 2010 Elsevier B.V. All rights reserved.

\section{Introduction}

One of the least questioned issues in economic literature (e.g., Bartel and Sicherman, 1998) is certainly the negative effects of higher technological progress rates on human capital stock. ${ }^{1}$

However, this agreement is no longer clear if, in contrast to the effect of technological progress rate on human capital stock, we focus on the effect of growth on human capital investment decisions.

Gould (2002), for example, maintained that the highest technological progress rates seen in recent years created an increase in the demand for general human capital, due to the greater adaptation of this type of investment to the constant changes implied by technical progress; while Murnane et al. (1995) maintained, on the other hand, that given the high obsolescence levels created by higher growth rates it would be more advantageous to invest in specific human capital, rather than in general human capital.

The main objective of this paper is to approach these apparently contradictory predictions, attempting to answer questions such as:

\footnotetext{
* Corresponding author. Av. da Universidade, 2700, $2^{\circ}$. andar. CEP: 60.020-181. Fortaleza, Ceará, Brazil. Tel./fax: +55 8533667751.

E-mail address: marciovcorrea@caen.ufc.br (M. Corrêa).

${ }^{1}$ The usual argument is that the higher the economic growth, the quicker the general and specific capital stocks lose value, due to the obsolescence created by the introduction of new knowledge and new production techniques.
}

given higher technological progress rates, what will be the best investment for the worker? What will be the impact of this decision on labor market outcomes, among them the unemployment rate?

\section{Theoretical models}

The two models that we will develop are based on Mortensen and Pissarides (1998), augmented with training investments, where the basic difference lies in the form of technological progress: creative destruction or renovation. We will consider in both models a more generic formulation for human capital investment, where the worker can invest in three types of human capital: human capital totally targeted at the market, without any value for the firm, human capital totally targeted at the firm, without any value for the remaining firms in the market, and human capital with value for the market and for the firm, as defended by Kuhn and Sweetman (1999).

\subsection{Creative destruction}

The economy is formed by a constant population of workers, who live infinitely, and a great number of firms, which once matched, one by one, give way to a production activity.

Before production, firms and workers are involved in a search process to find a partner, where $P(t) c$ measures the search cost for the firm and $P(t)=e^{g t}$ represents a common growth factor. 
The amount of job matches formed per period is given by the function $m(v, u)$, where $v$ represents the vacancy rate and $u$ the fraction of unemployed workers in the economy. The function $m$ is non-negative, concave, homogeneous of degree one and increasing in both arguments.

Let $P(\tau) x$ represent the production generated, in each time $t$, by a job match formed at moment $\tau$ and that, once production has begun, the worker may later decide whether to invest or not in human capital, at the cost $P(t) z$, and the final destination of investment.

The value functions for the firm and the worker ${ }^{2}$ are given by:

$$
\begin{aligned}
& r V(t)=-P(t) c+q(\theta)[J(t, t)-V(t)]+V(\dot{t}) ; \\
& r U(t)=\varepsilon P(t) x+\theta q(\theta)[W(t, t)-U(t)]+\dot{U(t)} ; \\
& r J(\tau, t)=\operatorname{Max}\left\{P(\tau) x\left[1+\delta(1-\psi)_{\nu, s}+\alpha_{\tau, t} \varphi \psi_{\tau, t}\right]-w(\tau, t)-\lambda[J(\tau, t)-V(t)]\right. \\
& +J(\dot{\tau}, t) ; r V(t)\} \\
& r W(\tau, t)=\operatorname{Max}\left\{\operatorname{Max}_{\substack{\alpha \in[0,1 \\
\psi \in[0,1]}}\left\{w(\tau, t)-\alpha_{\tau, t} P(t) z-\lambda[W(\tau, t)-U(t)]+W(\dot{\tau}, t)\right\} ;\right. \\
& \left.r U(t)+\delta \varepsilon(1-\psi)_{\nu, S} P(t) x+\alpha_{\tau, t} \delta \varepsilon(1-\psi)_{\tau, t} P(t) x\right\} .
\end{aligned}
$$

The first and the second expressions are the standard asset equations for the firm, with a job vacancy, and the worker, in the unemployment position. ${ }^{3}$

The expression ( 3 ) is the asset equation for the firm with an occupied job. It tells us that an occupied job produces $P(\tau) x\left[1+\delta(1-\psi)_{\nu, s}+\varphi \psi_{\tau, t}\right]$, if the worker has invested $(1-\psi)$ in training, at the time $s$ of his previous job, and $\psi$ in training, at the time $t$ of his actual job.

The expression (4) is also standard. The only difference is that once in unemployment the worker receives the common value of that position, $r U(t)$, plus the term related with his past and his actual training investment. ${ }^{4}$

\subsubsection{Wage determination}

We assume that the surplus generated by the matching is divided according to the Generalized Nash Bargaining Solution, where $\beta$ represents the worker's bargaining strength, then $w(\tau, t)$ satisfies:

$$
\beta[J(\tau, t)-V(t)]=(1-\beta)[W(\tau, t)-U(t)] .
$$

Using Eqs. (1)-(4) and free entry condition, we have

$$
\begin{aligned}
w(\tau, t)= & \beta\left\{P(\tau) x\left[1+\delta(1-\psi)_{\nu, s}+\alpha_{\tau, t} \psi_{\tau, t} \varphi\right]\right\} \\
& +(1-\beta) P(t)\left\{\omega(\theta)+\alpha_{\tau, t}\left[z+\delta(1-\psi)_{\tau, t} \varepsilon x\right]\right\},
\end{aligned}
$$

where

$\omega(\theta)=\varepsilon x\left[1+\delta(1-\psi)_{v, s}\right]+\frac{\beta c \theta}{(1-\beta)}$.

We can observe from Eq. (6) that if the worker decides to invest in training $(\alpha=1)$ the greater will be the worker's wage, for a given

\footnotetext{
2 Our focus in this paper is on the question of the optimal rule of training investments. We are not interested in questions of efficiency or questions related with the effect of human capital investments on the transition rate from unemployment to employment, already extensively covered in the literature (e.g., Acemoglu, 1997; Moen, 1999).

${ }^{3}$ The term $\varepsilon P(t) x$ is the opportunity cost of the job, whilst $\theta q(\theta)$ and $q(\theta)$ give us, respectively, the rate an employed worker moves to an employed situation and the rate a job vacancy moves towards a filled position.

${ }^{4} \alpha_{\tau, t}$ is a variable that represents the decision to invest in human capital, at the moment $t$, in a job created at $\tau . \psi$ measures the impact of human capital investment over the ongoing matching.
}

technological progress rate. Also note that the greater the technological progress rate, the higher will be the worker's wage rate.

The following Lemma shows the conditions under which the worker invests in human capital accumulation.

Lemma 1. Given the share of firm-specific human capital, $\psi$, if:

a) $\beta \psi \varphi P(\tau) x+(1-\beta) P(t) \delta(1-\psi) \varepsilon x \geq \beta P(t) z$, the worker invests in human capital;

b) $\beta \psi \varphi P(\tau) x+(1-\beta) P(t) \delta(1-\psi) \varepsilon x<\beta P(t) z$, the worker does not invest in human capital. ${ }^{5}$

Notice that if we consider that the advantages of investing in human capital totally targeted at the firm are greater than the advantages of investing in human capital totally targeted at the market $(\psi=1)$, then we will have the worker investing in human capital whenever $\varphi P(\tau) x \geq P(t) z$. In this way, the greater the technological progress rate, the lower will be the probability that the worker invests in human capital targeted at the firm.

In turn, if we consider that the advantages of investing in human capital totally focused on the firm are less than the advantages of investing in human capital totally focused on the market $(\psi=0)$, then the condition for investment is $(1-\beta) P(t) \delta \varepsilon x \geq \beta P(t) z$. Note, in this last case, that technological progress does not affect the probability of investment in human capital totally targeted at the market.

The following Lemma assumes that it is optimal to invest in human capital $(\alpha=1)$ and derives the optimal destination of this investment.

Lemma 2. Given the worker invests in human capital, $\alpha=1$, if:

a) $\beta \varphi P(\tau) x>\beta \delta P(\tau) x+2(1-\beta) \delta P(t) \varepsilon x$, the worker invests in human capital totally targeted at the firm;

b) $\beta \varphi P(\tau) x<\beta \delta P(\tau) x+2(1-\beta) \delta P(t) \varepsilon x$, the worker invests in human capital totally targeted at the market;

c) $\beta \varphi P(\tau) x=\beta \delta P(\tau) x+2(1-\beta) \delta P(t) \varepsilon x$, the worker invests in perfect general human capital. ${ }^{6}$

For a worker to invest in human capital totally targeted at the firm, it is necessary that the benefits he receives at moment $t$ be greater than the sum of the benefits he receives with the investment in human capital totally targeted at the market, at the same moment $t$, and those related to the investment in human capital targeted at the market at moment $s$.

\subsubsection{Job creation and Job destruction dynamics From Eqs (3) to (6) we have}

$J=(1-\beta) \int_{0}^{T}\left\{x[1+\delta(1-\psi)+\alpha \psi \varphi]-e^{g t}[\omega(\theta)+\alpha z+\alpha \delta(1-\psi) \varepsilon x]\right\} e^{-(r+\lambda) t} \cdot d t ;$

$J=\frac{c}{q(\theta)}$

$x[1+\delta(1-\psi)+\alpha \psi \varphi]=e^{g T}[\omega(\theta)+\alpha z+\alpha \delta(1-\psi) \varepsilon x]$

characterizing the optimal life of a job, $T$, in terms of market tightness and human capital investment decisions, and the optimum job creation rule in a stationary setting. ${ }^{7}$

\footnotetext{
${ }^{5}$ We assume, in a stationary setting, that if the costs of human capital investments are equal to benefits, the worker decides to invest in human capital. To show the previous lemma we need only to substitute Eq. (6) in Eq. (4) and differentiate it with respect to $\alpha$.

${ }^{6}$ We assume, in a stationary setting, that the worker invests in perfect general human capital, that is $\psi=(1-\psi)$, if indifferent between investing totally in the firm or totally in the market. As before, we only need to substitute (6) in (4) and differentiate it in terms of $\psi$.

7 Given the optimal human capital investment decisions, expressions (7)-(9) uniquely determine the steady state equilibrium in $T-\theta$ space.
} 
Proposition 1. Assume that $\varepsilon=0$, the human capital investment costs $(z)$ are low, so that the worker always invests in training, and the benefits received are such that the investment is in perfect general human capital. In this way, if there is a change in the relative benefits received by the investment, in a manner that $\psi$ varies to:

a) $\psi=1$, then the effects of human capital investment are an increase in the job destruction and job creation dynamics;

b) $\psi=0$, then the effects of human capital investment are a reduction in the job destruction and job creation dynamics.

Proof. We need only to differentiate Eqs. (7) and (9) in terms of $\psi$, consider Eq. (8) and Lemma 2 to demonstrate that the job creation increases while the job destruction decreases with $\psi=1$. Substituting Eq. (9) in Eq. (7), considering the Implicit Function Theorem and Leibniz Rule, we can demonstrate that as $\psi$ increases, $T$ also increases, due to the increase in $\theta$.

The idea behind the previous proposition is that when there is human capital investment, the worker's wage rate will be greater, and this induces a greater obsolescence rate, without necessarily bringing about an increase in the job matching productivity. In this way, if investment starts to be totally directed at the firm, the worker's investment decision leads to an increase in the job destruction and job creation flows, as the effect of the increase in the wage rate is greater than the effect of a higher job matching productivity generated by the investment. In turn, if the investment starts to be totally directed at the market, we will have the opposite effect.

\subsubsection{Unemployment}

Now, because in the steady state the job creation (JC) flow equals the job destruction (JD) flow, we have

$J C=\theta q(\theta) u=\lambda(1-u)+e^{-\lambda T} J C=J D$.

In this way, we have

$u=\frac{\lambda}{\lambda+\theta q(\theta)\left(1-e^{-\lambda T}\right)}$,

representing the equilibrium unemployment rate.
Note from this expression that the entire effect of human capital investments over the unemployment rate occurs via $\theta$ and $T$. Therefore, the lower is $\theta$ or $T$, the higher will be the unemployment rate.

\subsection{Renovation}

The model in this section is similar to the previous one, except that if the worker decides to invest in human capital totally targeted at the firm, his actual job matching jumps to the technological boundary. ${ }^{8}$

Using the same steps as before, which we will not repeat for the sake of brevity, we can observe some basic characteristics behind the renovation model, namely:

- the higher the technological progress rate, the greater is the probability of the worker investing in human capital totally targeted at the firm:

- the more the investment is directed at the market the greater is the job destruction and job creation flow.

\section{Acknowledgement}

Financial support by FCT (Fundação para a Ciência e a Tecnologia), Portugal, and FUNCAP (Fundação Cearense de Apoio ao Desenvolvimento Científico e Tecnológico), Brazil, are gratefully acknowledged. This article is part of the Multi-annual Funding Project (POCI/U0436/ 2006).

\section{References}

Acemoglu, D., 1997. Training and innovation in an imperfect labor market. Review of Economic Studies 64, 445-464.

Bartel, A., Sicherman, N., 1998. Technological change and the skill acquisition of young workers. Journal of Labor Economics 16, 718-755.

Cavalcanti, T., 2004. Layoff costs, tenure, and the labor market. Economics Letters 84 383-390.

Gould, E., 2002. Rising wage inequality, comparative advantage, and the growing importance of general skills in the United States. Journal of Labor Economics 20 105-147.

Kuhn, P., Sweetman, A., 1999. Vulnerable seniors: unions, tenure and wages following permanent job loss. Journal of Labor Economics 17, 671-693.

Moen, E., 1999. Education, ranking and competition for jobs. Journal of Labor Economics 17, 694-723.

Mortensen, D., Pissarides, C., 1998. Technological progress, job creation and job destruction. Review of Economic Dynamics 4, 733-753.

Murnane, R., Willett, J., Levy, F., 1995. The growing importance of cognitive skills in wage determination. The Review of Economics and Statistics 77, 251-266.

\footnotetext{
${ }^{8}$ Cavalcanti (2004) used a similar idea to study the effects of layoff costs, which increase with tenure, over the labor market.
} 